Fecha de recepción: diciembre 2018 Fecha de aceptación: marzo 2019 Versión final: junio 2019

\section{Las figuras femeninas y su representación musical en la película Safo, historia de una pasión (1943)}

Rosa Chalkho *

Resumen: El artículo se propone estudiar la relación entre la música y las figuras de la mujer representadas en la película Safo, historia de una pasión dirigida por Carlos Hugo Christensen. El director inaugura un cambio en la cinematografía de la época al introducir a principios de la década del '40 temáticas audaces como el erotismo, las pasiones turbulentas, el suicidio, las traiciones o el divorcio.

El encargado de la música es George Andreani, un compositor nacido en Varsovia en 1901 que se forma musicalmente en Berlín, Viena y Praga, y que antes de llegar a la Argentina, huyendo del nazismo, ya había compuesto numerosas bandas musicales y recibido premios en Checoslovaquia y Francia. A partir del film El inglés de los güesos (1940), Christensen y Andreani forman un tándem estrecho entre director y compositor, como queda evidenciado en los más de veinte títulos en los que trabajan juntos

La cohesión compositiva de la música está basada fundamentalmente en el uso del leitmotiv de impronta wagneriana que se presenta asociado a los personajes de Selva, la femme fatal, Irene la adolescente ingenua y Teresa, la tía santa. En forma paralela a la construcción musical de los personajes, la banda musical se adhiere al arco dramático subrayando los climas y emociones. Andreani maneja la orquestación con pericia mediante un uso rico y contrastante de la paleta tímbrica, explotando los recursos de los lenguajes romántico y post-romántico.

El personaje de Selva (la femme fatal) interpretado por Mecha Ortiz está asociado leitmotívicamente a un vals lento y pastoso, trabajado con ritmos apuntillados y con la melodía a cargo de las cuerdas, tocada con portamentos connotando la sensualidad y densidad de esta mujer experimentada. Es el motivo más desarrollado a lo largo del film y el que sufre las mayores transformaciones. Su progresiva ruptura y fragmentación construida mediante contrastes de registro, orquestación y ritmos, genera la variedad de climas conforme la trama se tensiona.

Como contraposición, el motivo musical de Irene (la ingenua) interpretado por Mirtha Legrand es elegante y brillante, asociado al tópico musical del minuet. La banda sonora presenta un tercer motivo, asociado a Teresa (la tía del protagonista) construido en base al tópico de "la mañana", de carácter pastoral y bucólico no sólo representa al personaje sino también al espacio rural idílico y católico.

Uno de los hallazgos del trabajo es la relación entre los estereotipos de mujer que aparecen en las películas y su trascendencia más allá de la pantalla en la vida de las actrices, cuestión que se verifica en la representación de las estrellas del cine en las revistas de la época de manera análoga a las figuras que representan en los filmes, tanto en las fotografías como los textos y entrevistas. 
El artículo toma como enfoque teórico a la teoría de género, en particular, a las aplicaciones de esta perspectiva para estudiar el cine y la música, como el trabajo pionero de Laura Mulvey para el cine clásico (Mulvey, 2001), el libro germinal de Susan McClary que aborda la música desde una musicología feminista (McClary, 2002) y los enfoques más recientes de Pilar Ramos López (Ramos López, 2003) y Laura Viñuela (Viñuela Suárez, 2003). Para el abordaje del análisis musical consideramos a la Teoría Tópica, (Ratner, 1980) que permite desentrañar la construcción del sentido musical a través de los tópicos como unidades discursivas que cobran sentido en un contexto sociocultural.

Metodológicamente, realizamos un cruce entre las herramientas del análisis musical con el análisis fílmico atravesado con el marco teórico propuesto y complementado con fuentes documentales como entrevistas y artículos de prensa de la época.

Palabras clave: Música cinematográfica - Cine clásico argentino - Figuras femeninas Carlos Christensen - George Andreani - Leitmotiv

[Resúmenes en inglés y portugués en las páginas 164 - 166]

(*) Profesora Nacional de Música (Conservatorio Nacional "López Buchardo"), Profesora de Artes en Música (IUNA), Magister en Diseño (UP), Doctoranda, Facultad de Ciencias Sociales (UBA). Docente de Historia y de Comunicación en la Facultad de Arquitectura, Diseño y Urbanismo (UBA); Profesora de Estética y Técnica del Sonido en la Facultad de Diseño y Comunicación (UP), Directora de la Escuela de Música № 7 DE 11, GCBA. Ha dictado seminarios en la Maestría y Doctorado de la UP. Es investigadora principal del IAA - Instituto de Arte Americano e Investigaciones Estéticas "Mario Buschiazzo" FADU(UBA). Ha publicado varios artículos y comunicaciones en revistas científicas y congresos en Argentina y el exterior como resultado de su investigación.

\section{Introducción}

A diez años del primer largometraje sonoro argentino, y transcurrida una década de creciente e intensa producción cinematográfica, se estrena el 17 de setiembre de 1943 en Buenos Aires Safo, historia de una pasión, película considerada como el primer melodrama erótico argentino ${ }^{1}$.

Me propongo analizar las figuras de la mujer representadas en el film, y en particular, estudiar los modos en que la música aparece asociada a los personajes y participa en la construcción del sentido, tanto de las figuras de mujer como de los climas de la narración. En forma paralela, nos interesa caracterizar lo musical en este tipo particular de enunciación cinematográfica definido como el melodrama clásico, para detectar qué aspectos de la película adscriben al canon del clasicismo y en qué innovaciones se plantean como ruptura. 
El film fue dirigido por Carlos Hugo Christensen sobre la novela francesa Sapho (1884) de Alphonse Daudet adaptada por César Tiempo y Julio Porter, con producción de los estudios Lumiton y música de George Andreani. Ambientada a fines del siglo XIX relata la relación tormentosa de un joven con una mujer sensual y experimentada ${ }^{2}$.

\section{El argumento}

Raúl de Salcedo (Roberto Escalada), un joven mendocino de familia conservadora y católica, consigue por intermedio de su tío un trabajo que le permitirá comenzar su carrera profesional en Buenos Aires. El tío Silvino (Miguel Gómez Bao) es un juerguista vinculado con la burguesía y la bohemia porteña, que ni bien llegar a la ciudad, lleva a Raúl a una lujosa y picaresca fiesta de carnaval en la donde el joven conoce a Selva (Mecha Ortiz). Desde las escaleras, al lado de la estatua desnuda y sugerente de la poetisa Safo, Selva observa a Raúl. Fumando, hierática, envuelta en tules y serpentinas no tarda en ir a su encuentro para seducirlo e irse con él esa misma noche.

A día siguiente, luego de lo que parecía una aventura pasajera con Selva, Raúl conoce a Irene (Mirtha Legrand), el tercer vértice del triángulo amoroso que motoriza la trama. Irene es la antítesis de Selva, una joven señorita ingenua de familia principal, hija del sr. Benavidez (Nicolás Fregues) quien le ha conseguido el puesto en un ministerio.

Raúl llega a la residencia de los Benavidez en un carnaval totalmente distinto, a plena luz del día, con inocentes juegos de agua y risas en los jardines de una mansión. Enseguida es bien recibido y su imagen de galán serio, responsable, trabajador y preocupado por su futuro lo convierte en el candidato ideal para Irene.

A partir de esta presentación, la trama oscilará entre la atracción irresistible de Raúl por Selva y su vuelta a la seguridad del amor ideal y respetable de Irene. El joven cae enfermo, y es Selva quien lo cuida y lo cura, mostrando una faceta abnegada y maternal del personaje de femme fatal. A partir de ese momento, Selva y Raúl inician una vida juntos en una modesta casita de los suburbios que se ve perturbada cuando él se entera en una mesa de café sobre el pasado de Selva y sus varios amores en ese ambiente de bohemia artística. Fue modelo para Caudal, escultor de la estatua de Safo para quien posó "desnuda como una lágrima” (00:54:26) y cuyas reproducciones aparecen simbólicamente de manera ubicua durante toda la película. Fue también musa inspiradora de los poemas encendidos de Molina, además de arruinar al dibujante Carbone que está en la cárcel por falsificar dinero para sus caprichos.

En un arranque de rescate moral, Raúl la abandona retornando a su bucólico pueblo natal, lugar de las virtudes, la religión y la familia. Allí se reencuentra con Irene, que había sido enviada por su padre para mitigar la melancolía en la que se sumió al darse cuenta que Raúl estaba con otra. Los festejos con música folklórica y bailes tradicionales con motivo de la asunción como intendente del padre de Raúl, son el marco para el reencuentro con Irene y el comienzo de un noviazgo que cuenta con el beneplácito de ambas familias.

De vuelta a Buenos Aires, y planeando el compromiso, Raúl decide ir a buscar unas cartas comprometedoras a lo de Selva, para cerrar esa historia del pasado. La encuentra trabajan- 
do al servicio de una pensión, ya que no quiso aceptar la ayuda de sus antiguos amigos y prefirió esperarlo en esta humilde condición. Raúl irá esa noche a la casita de los suburbios en la que Selva aún vive con el único fin de buscar las cartas, pero en esa visita la pasión incontenible entre los dos se desata nuevamente.

Raúl rompe el compromiso con Irene, decidido a quedarse con Selva, pero ella finalmente decide irse con Carbone que salió de la cárcel, dejándole una nota de despedida. Raúl desesperado rompe en llanto y el film termina.

\section{El contexto}

Carlos Hugo Christensen se interesa tempranamente por el cine, la radio y la literatura. Comenzó muy joven realizando radioteatros en Radio Splendid que cobraron éxito y llamaron la atención de César Guerrico, uno de los dueños de Lumiton que lo convoca al estudio: "Al día siguiente, prácticamente, ya estaba en Munro3 , asistiendo a la filmación de Así es la vida" (1939) (Gallina, 1997, pág. 109). Christensen se mudó a un chalé dentro del predio del estudio y se pasaba el tiempo empapándose de las técnicas de realización cinematográfica. En poco tiempo con 26 años estrena El inglés de los güesos (1940) basada en la novela homónima de Benito Lynch.

Su afición literaria, como lector y escritor, explicaría que gran parte de sus películas son adaptaciones de novelas, muchas de ellas de autores extranjeros, y esta cuestión colaboró con la construcción de un estilo internacional que atrajo al público de las clases medias más afecto al cine norteamericano. En el reportaje que le realizó Mario Gallina el 25 de agosto de 1996 en Rio de Janeiro señala:

Nuestro cine ocupaba un lugar importantísimo, muy cerca del norteamericano, en lo referente a recaudaciones en todo el mundo. Creo que la gran virtud radicaba en su casi sorprendente diversidad temática. Si hubiésemos hecho como los mexicanos, que se dedicaron a argumentos demasiado localistas, jamás podríamos haber capturado otros públicos. Ese tránsito por temas extranjeros -sin excluir los nuestros- fue el que nos abrió las puertas en todas partes. (...) Porque era un cine con tendencia internacionalista, que llegaba e interesaba a distintos públicos. Por supuesto que en el caso de argumentos foráneos ¡había que saber adaptarlos! (Gallina, 1997, pág. 114)

Esta preocupación por las dualidades de lo local - extranjero, o nacional - internacional que plantea Christensen en la cita anterior está omnipresente en la cinematografía argentina clásica, en los discursos de la época, en los contenidos de los films y en los modos y condiciones de producción. Como afirma Matthew Karush: "los estudios de cine argentinos elaboraron un estilo cinematográfico que combinaba elementos de Hollywood con un localismo autoconsciente" (Karush, 2013, pág. 26).

Esta combinación particular de aspectos internacionales como signos y técnicas de modernidad procesados con temáticas y estilos vernáculos ha sido definida por Beatriz Sarlo 
como "modernidad periférica" (Sarlo, 1988) y caracterizada por Nicola Miller como un proceso "desparejo y dependiente" que combina dependencias económicas, procesos de apertura política, fuerzas renovadoras en el campo cultural y sectores tradicionales con prácticas residuales y conservadoras (Miller, 1999).

Técnicas y enunciación fílmica internacional con temas y estilos locales conforman estas producciones. Estas tensiones y apropiaciones entre lo local y lo internacional resuenan en la cristalización de otros pares de opuestos maniqueos presentes en las películas, que, en casi todos los casos, cargan además con atributos simbólicos morales o moralizantes. El campo y la ciudad, el tango y el jazz 4 , la tradición y la modernidad, la femme fatal y la ingenua son algunos de estos dualismos estereotipados que las películas adoptaron y ratificaron.

En Safo el primer contraste que observamos es territorial, con la oposición campo - ciudad. El espacio rural, la provincia de Mendoza, es el lugar de la familia, el catolicismo y las virtudes morales que descansan en la tradición y representan la argentinidad. Esta imagen de lo nacional es campestre, con paisajes diurnos y luminosos, vestuarios de gaucho estanciero y de paisana, estilizados y pulcros. La música folklórica es la imagen sonora de la Nación, en este caso, con la canción en la diégesis de una cueca interpretada por el conjunto de Féliz Pérez Cadozo con una coreografía estilizada del baile en grupo con galanteos sutiles e ingenuos (1:04:02) ${ }^{5}$. Es el espacio de la madre de Raúl, de su joven y dedicada tía Teresa (esposa del mujeriego Silvino) y es el sitio donde Irene va a sanar su melancolía. En este contexto virtuoso se inicia el noviazgo socialmente legítimo entre Raúl e Irene.

Por el contrario, Buenos Aires la ciudad capital, es el lugar del lujo en las mansiones, la bohemia en las reuniones de café, los brillos y gasas en los trajes femeninos, la noche, la diversión y, en especial, la perdición de Raúl en poder de una mujer que toma la iniciativa en la seducción y de cuyo magnetismo no podrá escapar. Es el terreno de Selva, la femme fatal, la mujer experimentada dueña de sus encantos, pero también dueña de un pasado complejo. Su insinuada modernidad está representada especialmente por la música, con el atrevido baile del can-can en la fiesta de carnaval. Lo cosmopolita también como signo de lo moderno se escucha en los valses de la fiesta, en la pieza de salón que toca Irene al piano y en el vals que suena en la victrola.

Existe un tercer espacio conformado por el suburbio, donde Raúl y Selva alquilan su modesta casita. Es el lugar que propone ella como refugio para los dos y se conforma como un territorio virtuoso que los aleja de aquel pasado libertino de la ciudad. Pero a diferencia del pueblo mendocino, lo moral está asociado a la austeridad económica, y como resalta Karush, se ajusta a la representación tan frecuente en el cine de esta época de valores nacionales de virtud y pobreza en donde las clases obreras y populares son las que detentan la reserva moral de la sociedad. Funciona como un espacio transitorio entre redención y perdición ${ }^{6}$.

La oposición dualista explica también las figuras de la mujer. Selva e Irene se configuran en el film como personajes contrapuestos, tanto en la conformación dramática de la ingenua y la femme fatal como en la funcionalidad del relato: las dos persiguen el amor de Raúl aunque sus universos no se tocan y ellas casi ni se cruzan ${ }^{7}$. Sus esferas sociales son distintas: Irene pertenece a una elite burguesa y Selva no tiene dinero ni familia. 


\section{Las mujeres: un enfoque teórico de la música y el cine}

En relación a las lecturas de las figuras de mujer, consideramos que la teoría feminista ha producido una total transformación tanto en los enfoques de la academia como en la vida social a partir de la desnaturalización del modelo hetero-normativo y sexo-genérico. Es así que cuando visitamos estas figuras estereotipadas del cine de la década del '40, no podemos dejar de ver desde la perspectiva actual, el derrotero histórico mediante el que se conformaron los atributos genéricos naturalizados de lo que las mujeres "son", y de los cuales el cine y la música como productos dilectos de la cultura de masas formaron (y forman) parte sustantiva.

En este sentido, reponemos el trabajo germinal de Laura Mulvey Visual Pleasure and $\mathrm{Na}$ rrative Cinema ([1975] 1992), que plantea desde un enfoque psicoanalítico la representación de la mujer en el cine clásico como objeto para la mirada del hombre, como lo desarrolla en el apartado "La mujer como imagen, el hombre como portador de la mirada (Mulvey, 2001, pag. 370)”.

Mulvey señala además, que esta construcción es paradojal, ya que al tiempo que la figura de mujer es objeto escópico dado al hombre, en la narrativa aparece como elemento amenazante que irrumpe el devenir de la diégesis, interpelando la mirada misma del espectador ${ }^{8}$. En Safo, se observa también claramente este juego de imágenes, miradas y roles que Mulvey pone en evidencia en el cine de Hollywood. Los personajes de Selva e Irene constituyen su subjetividad en tanto conforman el vínculo con un hombre y están dados a su mirada. En el caso de Selva, además, su vida está moralmente cuestionada debido a su relación con otros hombres. En el caso de Irene, es su padre (su madre no está en el relato) el que actúa como regulador de su vida.

La objetivización en particular del personaje de la ingenua se evidencia en la escena del pedido de mano de Raúl al padre de Irene y más aún, en la escena en que él rompe el compromiso sin decirle nada a ella. Simplemente habla con el padre y no le da ninguna explicación a Irene que le reclama llorando por qué no le habla.

La categoría de "film erótico" es una consideración que la crítica ha repetido sin cuestionamientos y que creemos que podría ser revisada. De hecho, Christensen insiste en que su intención fue retratar escenas de amor "verdadero", con besos creíbles y apasionados a diferencia de otros films en que, a su entender, estas escenas se veían ridículas. (Russo \& Insaurralde, 2013).

Con respecto a la representación del espacio erótico, nos interesa destacar algunas metáforas con las que el filme alude a la relación sexual, como el plano de una lámpara titilando (00:18:30), las olas del mar y la tormenta combinado con el plano de la estatuilla de Safo, que se suceden luego que Selva le dice a Raúl: "no tenés curiosidad por ver mi dormitorio? Vení" (00:33:55).

Gran parte de la osadía que el filme presenta para la época está asentada en el lenguaje, como se aprecia en la invitación de Selva a su dormitorio . Por su parte, las imágenes insinúan más que lo que muestran, en particular gracias al vestuario decimonónico que cubre todo el cuerpo, mientras que la carga erótica visual recae fuertemente en las miradas y los símbolos (la estatua desnuda). 
Como lo analizan Soledad Pardo y Pablo Croci, resultan muy relevantes los elementos simbólicos del filme: la estatuilla omnipresente de Safo y las telarañas, como símbolo de Selva, la mujer araña que va atrapando a Raúl en sus redes (Pardo \& Croci, 2011).

Otro elemento insoslayable, se conforma con el timbre de voz diferenciado entre las mujeres. Selva tiene una voz grave y un hablar cadencioso, mientras que la voz de Irene está en un registro agudo, con una entonación liviana y aniñada. Las tradiciones que ubican lo bello y bueno en lo agudo y lo temible y peligroso en lo grave tienen raíces históricas que se observan en la conformación del registro de soprano de la heroína de ópera ${ }^{10}$.

Desde la Musicología resulta una referencia pionera el libro de Susan McClary Feminine endings. Music, Gender \& Sexuality. ([1991]2002) que inaugura un campo de investigaciones especialmente rico en los últimos años. Pilar Ramos López (2003) advierte un desembarco tardío de la teoría feminista en la musicología que ha empezado a reponer estas vacancias. Una de las líneas, es justamente el análisis de las representaciones de género en la música. Es decir, qué connotaciones, significados y asociaciones operan desde lo musical en los procesos de identificación de género.

Por su parte, Laura Viñuela (2003) en su artículo La construcción de las identidades de género en la música popular recupera un estudio realizado por Phillippe Tagg (1982) en el que hizo escuchar a un grupo de personas fragmentos musicales instrumentales para cine o televisión y sus respuestas fueron coincidentes y estereotipadas respecto al género. De acuerdo con Tagg, suscribimos al poder performativo del audiovisual en la construcción social del sentido, y para este caso, en la construcción de modos de ser mujer en los '40. El trabajo de Viñuela aborda algo evidente y al mismo tiempo poco estudiado respecto de los consumos musicales: la existencia de géneros musicales para mujeres (pongamos por ejemplo canción popular romántica) y para hombres (como por ejemplo el heavy metal).

Lo que esta corriente musicológica ha puesto en evidencia es cómo la heteronorma aparece en lo musical y como además estos rasgos musicales heteronormados refuerzan desde los consumos culturales los estereotipos de género. Es así como, por ejemplo, lo melódico como elemento musical portador de la expresividad y la sensibilidad es caracterizado como "femenino" y la armonía, como construcción racional elaborada es asociada a "lo masculino". En Safo, como veremos más adelante, los motivos musicales están asociados únicamente a los personajes de mujeres y compuestos en base a tópicos musicales asociados a lo femenino, como los tópicos de danza del vals y el minuet.

Con este enfoque, abordamos esta doble construcción (cinematográfica y musical) de las figuras femeninas representadas en el film y su comprensión dentro del contexto en el que fueron producidas.

\section{La ingenua}

A principios de los '40, el estereotipo de la ingenua irrumpe en la escena cinematográfica de la mano del director Francisco Mugica. Encarnadas por las nacientes y adolescentes estrellas María Duval y Mirtha Legrand esta configuración femenina aparece como una novedad frente a las figuras de la década del '30, cuando predominaban las mujeres del 
tango (la milonguita, la arrabalera, la chica de barrio), la heroína sufriente como quintaescencia del melodrama y la figura de la mujer trabajadora que introduce luego el director Manuel Romero.

Gabriela Fabbro traza la propia genealogía de los estudios Lumiton en relación a los directores y el tratamiento de las figuras de mujer:

Ya en Mujeres que trabajan Manuel Romero había introducido la temática de la mujer en el cine de Lumiton (...), pero es Mugica quien presenta un nuevo arquetipo femenino: el de la jovencita ingenua, que dará letra a gran parte de la producción del futuro del cine nacional. (...) el tercer director estrella del estudio, Carlos Hugo Christensen provocará un vuelco en el tratamiento del arquetipo de la mujer con la presentación de una femme fatal y enigmática. (Fabbro, 2000, pág. 237)

El cambio de Christensen no sólo consiste en el agregado de una figura opuesta a la ingenua, sino que también producirá una complejización de esa cándida que dejará de serlo, a partir de personajes interpretados por jovencitas cuya trama se vuelve turbia, como el intento de suicidio de Dieciseis años (1943) de la adolescente conflictuada, el divorcio de La señora de Pérez se divorcia (1945), el sacrificio adolescente de El ángel desnudo (1946) entre otras (Kelly Hopfenblatt, 2014).

El sistema de estrellas y el sistema de estudios que cimientan la categoría de cine clásico tiene un especial funcionamiento en la construcción de analogías entre las estrellas y sus papeles. Es decir, la profusa exhibición de la vida de las estrellas en las revistas de la época construye un discurso que refuerza el estereotipo. La vida de las actrices es contada como una vida de película.

Como ejemplos, citamos un reportaje a Mirtha Legrand publicado en Radiolandia el 27 de enero de 1945 cuya introducción cuenta:

Muchacha pueblerina, como tantas, su vida comienza bajo el signo de la predestinación hogareña. Nada puede hacer creer que esta rubita, que pasea por las calles de su alegre población santafesina, brillará algún día en las rutilantes carteleras del cine. Ella misma jamás ha soñado con otra cosa que sus muñecas. $(1945, \mathrm{~s} / \mathrm{p})$

Esta simbiosis entre estereotipo de personaje y vida estelar también se verifica en el descontento posterior de Mirtha Legrand con el film, tanto por el rol secundario que interpretó como por la temática osada o "non santa" del film, como lo expresa en el reportaje que le realizó Mario Gallina publicado en $1997^{11}$.

\section{Un quiebre al canon: la femme fatal}

Las figuras femeninas y su correlato con los temas que las películas tratan, son modelos espectaculares en diálogo con los públicos. Claudio España (2000) señala que el cine de Christensen invita a un nuevo grupo social al cine argentino atraído por la internaciona- 
lización de la temática, la sofisticación del guión, los valores de producción y realización como aspectos diferenciados de las comedias costumbristas, los temas tangueros o los personajes vernáculos arquetípicos.

Uno de estos cambios fue la introducción de una nueva figura de mujer: la femme fatal. Una mujer seductora, segura de sí misma, experimentada, que sabe lo que quiere y que puede manipular a los hombres a su antojo. La actriz Mecha Ortiz comienza a actuar en cine con personajes de mujer formada. El tono grave y sugerente de su voz, su porte, su mirada penetrante y el gesto desafiante le valieron el mote de la Greta Garbo argentina. "Mecha Ortiz fue la perdición de los hombres. (...) la diva cautivadora, la mujer "para aprender", la dama desgarrada por dejar pasar a tantos hombres que solo aprovecharon sus encantos" (España, 2000, pág. 98)

Esta cita, refuerza el argumento que explicamos anteriormente: los estereotipos de feminidad trascienden la pantalla generando un entramado de discursos e imaginarios sobre las propias actrices, Mecha Ortiz es ésa.

Al respecto, reponemos una pequeña nota de la revista Radiolandia del 12 de mayo de 1945 que cuenta que Mecha Ortiz concurrió a una velada de boxeo y que sentada en el ringside recibió aplausos y muchísimos pedidos de autógrafos de boxeadores y admiradores. En medio de su pelea, un boxeador se distraía para mirarla y su rival lo tumbó. La nota reproduce los reproches y quejas del entrenador Juan Gómez que le dice a su pupilo: “- ¿Viste?... Te dije. Vas a sentir los pajaritos. -Y encarándose con Mecha Ortiz desde el 'ring', le gritó: -Usted tiene la culpa señora. Yo se lo dije pero él seguía mirándola... y claro” (Radiolandia, 1945, s/p)

La femme fatal tiene la culpa de la ruina de los hombres. A pesar que el personaje de Selva en el filme está cargado de simbolismos de vamp, como las sombras de telas de araña con las que atrapa a Raúl, humo envolvente y luces titilantes, también tiene una faceta de mujer abnegada y de fortaleza para sobreponerse a múltiples vicisitudes. Su persecución no es perversa, realmente ama a Raúl apasionadamente como también amó a los otros.

"Cuando una mujer quiere ser libre, sin depender de los hombres debe pagar su libertad con sufrimiento" (00:48:30) dice Selva mientras pasean en bote con Raúl en el Rosedal, reforzando el costo de ser una mujer independiente.

Selva es Safo, la modelo de la estatua de la poetisa griega. Aunque la cuestión lésbica no aparece en el libro ni en el film, llama la atención la elección del nombre: la mujer cortesana, sexualmente irresistible aparece vinculada en el imaginario masculino a lo lésbico mediante su apodo.

\section{Los motivos musicales de las mujeres}

En este apartado analizaremos el modo en que la música construye sentido en el filme a partir de leitmotivs asociados a los personajes. La primera evidencia es que los leitmotivs pertenecen solamente a los personajes femeninos y no hay leitmotiv para Raúl.

La segunda cuestión es que existen características musicales en estos motivos que, siguiendo a Susan McClary y su idea de la música como un discurso marcado por la idea de género (Ramos López, 2003), que podemos interpretar como femeninas: el motivo de 
Selva, el motivo de Irene y un tercer motivo asociado a Teresa, la tía de Raúl. En todos los casos, las entradas musicales construyen el clima de las escenas, refuerzan las emociones y marcan los arcos narrativos.

Para explicar estos sentidos musicales, tomamos los postulados de la Teoría tópica de la música que identifica tópicos o temas como unidades que cobran sentido mediante su uso y circulación en universos culturales compartidos ${ }^{12}$. En virtud de que el lenguaje musical dominante del cine clásico (en la banda incidental) es el sinfonismo romántico y post romántico, los tópicos identificados pertenecen al repertorio de tópicos de estas músicas ${ }^{13}$. La música de la película fue escrita y dirigida por el compositor judío George Andreani, que nace en Varsovia en 1901 y se forma musicalmente en Berlín, Viena y Praga. Antes de llegar a la Argentina (1937) escapando del nazismo, ya había realizado treinta y ocho bandas musicales en Checoslovaquia y Francia entre las que se cuenta la premiada El Golem $(1935)^{14}$ (Glocer, 2018).

Christensen y Joseph Kumok (el nombre de nacimiento de Andreani) forman un tándem estrecho entre director y compositor que queda evidenciado en los más de veinte títulos en los que trabajaron juntos ${ }^{15}$. Las pasiones turbulentas, lo erótico, el suicidio, las traiciones y los climas asfixiantes que se convirtieron en el sello distintivo de Christensen encuentran en la música de Andreani una expresividad densa y turbia para representar estas temáticas. El lenguaje compositivo de Andreani sigue el canon del sinfonismo cinematográfico romántico y post romántico, con un uso rico y versátil de la paleta orquestal y una estructuración formal basada en el leitmotiv de impronta claramente wagneriana con la espesura del denominado pathos romántico ${ }^{16}$.

El leitmotiv no es simplemente el anuncio de la presencia o la aparición inminente de un personaje, sino que el carácter con el que este motivo se corporiza anuncia el clima, las curvas de tensión y desenlace de la trama. Sus variantes acompañan el derrotero de los personajes, sus desventuras y momentos felices. Metafóricamente, la estructura que permanece estable, particularmente las notas, representan al sujeto, mientras que las variaciones del ritmo, el compás, la instrumentación, el registro, la velocidad y en especial el carácter representan las circunstancias, emociones y sentimientos que atraviesa en su camino.

El motivo central del film es el motivo de Safo (Selva) que se presenta a lo largo de toda la película, en la mayoría de las cues y con la mayor cantidad de variantes y contrastes. Está formado por cuatro notas con un intervalo de 5ta disminuida entre la segunda y tercera nota que sumado al diseño ascendente se constituye en tensión.

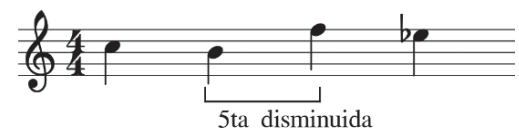

Motivo de Safo 
El film comienza con el motivo de Safo a modo de obertura brillante, orquestado con el grupo de los metales y un final ascendente. La función es la de opening o introducción del film en un procedimiento típico del cine clásico, independientemente del género o temática de la película, estos compases de apertura presentan un carácter marcial, heroico y brillante, equivalente a masculino:

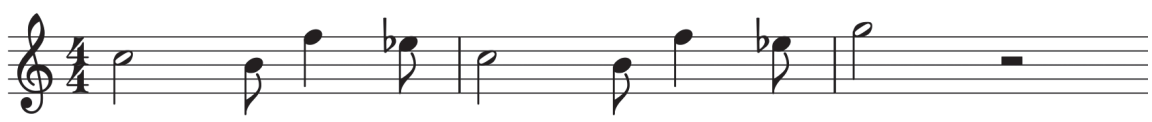

Introducción $^{17}$

Pero a los pocos segundos (00:00:28) el motivo cambia a un compás de 3/4 transformándose en un vals lento y denso, con una interpretación en las cuerdas con un arrastre del puntillo, que le confiere un carácter pastoso y sórdido:

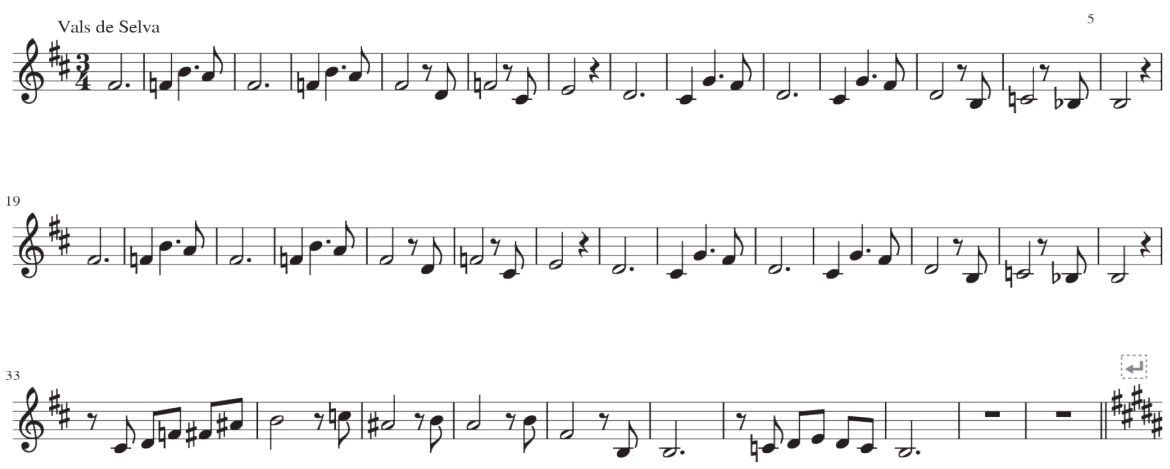

Vals de Safo

Durante la secuencia de títulos, el vals se ornamenta con variaciones en la orquestación como melodías en los vientos al final de las frases connotando lo femenino. Sobre el final de la entrada, aparece un recurso muy utilizado durante el romanticismo y en la música cinematográfica que consiste en escalas con diseños ascendentes y descendentes muy veloces en las cuerdas, y que funcionan como un efecto de agitación.

El film empieza con un plano panorámico luminoso del pueblo mendocino, y el vals del opening se articula con el siguiente motivo al que denominamos de "la mañana" ya que se inscribe en el tópico pastoral o de la mañana descripto por Raymond Monelle (2006) y que luego se asocia al personaje de la tía Teresa (00:02:05). Con un comienzo trabajado sobre el arpegio mayor y con la melodía a cargo del oboe sobre un acorde pedal en las cuerdas, esta entrada tiene las características pastorales y bucólicas del paisaje rural: 


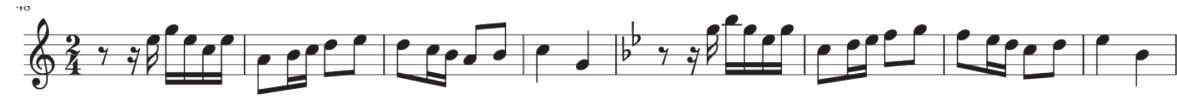

Motivo de Teresa o de "la mañana"

Sin embargo, la quietud no dura mucho, y la entrada comienza a tensionarse mediante trémolos en las cuerdas, connotando el nerviosismo por la espera de noticias sobre su futuro puesto en Buenos Aires que aguarda Raúl (00:02:21).

El motivo de Irene aparece recién a los treinta y ocho minutos de película, cuando ella y Raúl se despiden con un inocente galanteo. Refleja la felicidad de Irene y una suerte clima triunfal celebratorio del incipiente amor. Está en un compás ternario y en un estilo galante y brillante a la vez que permite encuadrarlo en el tópico del minuet:

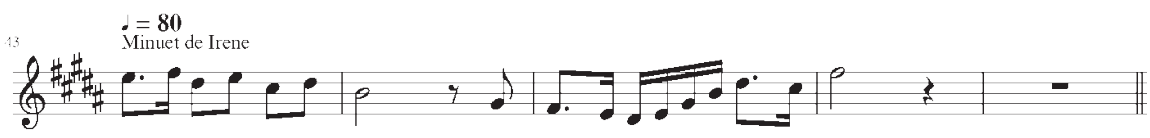

Motivo de Irene

Expuestos de este modo los motivos, analizaremos los modos en que se desarollan en la película, es decir, cómo se convierten en leit-motivos o motivos conductores de los personajes y la trama.

El motivo de Safo aparece luego de su presentación en los títulos de manera diegética en la fiesta de carnaval donde Selva y Raúl se conocen y bailan por primera vez. Mientras que durante la fiesta tocan otros valses, mezclados con el sonido ambiente, cuando ellos comienzan a bailar suena vals de Safo en un plano sonoro destacado, bajan las luces creando un clima sugerente mientras Selva le dice con su voz grave y seductora: "Vení, me lo vas a explicar bailando" (00:14:48). Es la primera asociación del motivo con el personaje de Selva y aparece con el mismo arreglo orquestal que en los títulos.

La segunda utilización se presenta en la escena siguiente cuando se van juntos de la fiesta a la pensión de Raúl, y él la sube en andas por las escaleras varios pisos. Aquí utiliza solo las cuatro notas del motivo (a diferencia de la melodía completa del anterior) en progresiones ascendentes connotando la subida por la escalera que, combinado con los pizzicatos en las cuerdas, un efecto de glissando de la flauta con golpe de percusión y arpegiado de arpa compone el tono de comedia o tópico de la ópera buffa (00:16:56) (Dickensheets, 2012). La persecución de Selva a Raúl está marcada por el motivo de Safo (00:26:07) cuando lo sorprende esperándolo en la pensión y el vals acompaña su fumar sensual con la melodía morosa en las cuerdas con portamento.

Esta es la última entrada en la que el motivo se explaya en la melodía del vals con las frases completas. A partir de aquí, las nuevas apariciones del motivo comienzan a aparecer fragmentadas, quebradas, incompletas o con cambios a un compás binario y con gestos bruscos y marcados reflejando la creciente tensión dramática de la trama. 
En la escena en que Raúl mira las fotografías del pasado de Selva el motivo se presenta cortado en la cuarta nota, sin resolver, combinado con diseños cromáticos descendentes y en registros y timbres contrastantes. La melodía se completa cuando Raúl ve la estatuilla de Safo, pero no resuelve la frase, sino que la tensiona hacia el agudo mediante trémolos y un motivo contrastante en el contrabajo (00:31:47).

Nos interesa destacar un momento significativo de la música en la escena de la alucinación febril de Raúl (00:40:50). En su delirio evoca a su tía Teresa, y la música combina fragmentos de los motivos de las tres mujeres, de manera cortada, fragmentaria y contrastante, apelando a las disonancias, los acordes tensionantes y contrastes extremos en los registros (contrabajos y vientos de madera agudos) para representar el desvarío. Esta escena es central también en coincidencia con la tesis de Mulvey, las tres mujeres se constituyen en tanto son imágenes del hombre, que se le aparecen mezcladas en su delirio. Esta cuestión se representa en la sobreimpresión de los rostros flotando delante de su sueño febril y en la música, que, de manera quebrantada, combina los tres motivos.

El motivo ganará en disonancia, tensión y ruptura y contrastes conforme se va desencadenando el drama, hasta llegar a uno de los puntos máximos del clímax dramático cuando Raúl, llegando al fin de la película, advierte desde afuera que el novio anterior de Selva que salió de la cárcel está con ella, adoptando el tópico de la tempesta típico de la ópera romántica (McClelland, 2014). El aumento de la tensión está construido por el sobreagudo en los violines y el motivo en los metales en forte. Nos interesa destacar una pequeña puntuación de la acción que colabora con el suspense de la escena: dos notas en contrabajo subrayan los dos pasos hacia atrás de Raúl cuando ve salir a el ex de Selva de la casa. (01:21:47)

El leitmotiv de Irene tiene intervenciones menores, al igual que su personaje cuasi secundario. No obstante esto, la ilustra claramente con un estilo elegante en tempo andante. Aparece desplegado en la secuencia en que Raúl e Irene pasean y cabalgan por los paisajes mendocinos (01:07:10), con una repetición variada como galop con el tópico de la cabalgata o noble corcel, y con la función de conducir la elipsis temporal de esas semanas en que se construye el noviazgo.

Por último, el leitmotiv de Teresa o de "la mañana" aparece pocas veces y asociado a la religión, en la cruz que lleva siempre Teresa y en el momento en que Raúl se persigna frente a un altar en las rocas antes de entrar a la casa familiar (00:59:40). Suena alegre y luminoso, y en esta entrada se desarrolla una segunda parte nueva con el mismo carácter, que se repite pasando la melodía a las cuerdas con un tono festivo que subraya la alegría de la llegada a casa y el abrazo con el padre.

\section{Reflexiones finales}

En el sistema de enunciación del melodrama clásico la música es un elemento central para el desarrollo dramático del film y como explicamos, para la construcción de la carga emotiva de los personajes mediante la asociación leitmotívica, cuyo resultado, además de "seguir al personaje", consiste en estructurar morfológicamente la banda musical reforzando su coherencia y los climas y emociones de la narrativa. 
¿Debería llamarnos la atención que en este film los leitmotivs pertenezcan únicamente a las mujeres? ¿Es esto una novedad? No realmente, el melodrama clásico y en particular el cine de Christensen están ciertamente focalizados en las emociones y los sentimientos de las mujeres. Heroínas sufrientes, mujeres sacrificadas, niñas inocentes o fermme fatales poblaron la pantalla de un espectáculo que contaba con mujeres como su público mayoritario. También eran mujeres las que leían las revistas sobre el cine y sus estrellas locales e internacionales. Sin embargo, coincidiendo con Mulvey, la representación de la mujer es la de una figura dada a la mirada del hombre, y en esta película, el personaje de Selva/ Safo encarna especialmente el foco del placer escópico masculino. Mencionamos como momento paradigmático de este juego de miradas a la escena en que Selva y Raúl van a la pieza de la pensión por primera vez: un plano medio de ella inmóvil, mirándolo bajo una luz titilante durante casi seis segundos, a punto de romper el pacto diegético su mirada atraviesa la pantalla e interpela al espectador. Un contraplano de Raúl petrificado y con los labios entreabiertos mirándola durante más de diez segundos, con el acompañamiento del vals de Safo en las cuerdas y con la melodía completa (00:18:05).

Retomando la cuestión musical, los leitmotivs de Selva e Irene son motivos asociados a tópicos de la danza: el vals y el minuet respectivamente. Los dos tienen compás ternario cuya métrica se ha asociado tradicionalmente con lo femenino, pero el vals de Safo es sensual, turbio y envolvente mientras que el minuet de Irene el elegante y brillante.

Nos interesa recuperar en estas conclusiones el trabajo de Eric McKee sobre los tópicos del vals y el minuet: Decorum of the Minuet, Delirium of the Waltz (McKee, 2012). A partir de un análisis de los tópicos de vals y minuet en la música académica del siglo XVIII y XIX, McKee encuentra asociaciones de despliegue, sensualidad y celebración en el vals (delirium) y connotaciones de decoro, contención y virtud en el minuet (decorum). Estos sentidos asociados a estas dos danzas, bastante emparentadas entre sí por rasgos musicales comunes, están funcionando plenamente en la música de la Safo.

El trabajo sumamente detallado en la partitura de George Andreani logra un despliegue notable de recursos simbólico - musicales en relación a la estructura dramática de la película conforma un estilo precursor en el cine argentino, asentado especialmente en su pericia para orquestar y en un dominio acabado del oficio. Ya en Dieciséis años estrenada el mismo año y también dirigida por Christensen, Andreani alcanza una gran coherencia musical mediante el desarrollo de los motivos a lo largo de la película. Podemos atribuir esta creciente solidez musical a la aceitada relación con el director en esta Safo, su octava película juntos.

\section{Notas}

1. El film está disponible en la plataforma del cine argentino Cinear play: https://play. cine.ar/INCAA/produccion/141/reproducir y en Youtube: https://www.youtube.com/ watch?v=BDFqgWsTXx4\&t=3972s

2. La película no da claves de la fecha en que transcurre la acción y en dos entrevistas distintas Christensen aporta datos diferentes de la época. En el reportaje realizado por Mario Gallina en 1996 y publicado en Carlos Hugo Christensen. Historia de una pasión cinematográfica, el director sitúa la acción en 1914 (el mismo año de su nacimiento) y se 
refiere particularmente al modo en que se documentó para incluir la música y coreografía del Can Can tradicional en la compleja y lograda escena del carnaval: "Los asesores a los que recurrí me informaron que era un baile obligado en esa época" (Gallina, 1997, pág. 111). En la entrevista realizada por Guillermo Russo y publicada en Más allá del olvido (2013) Christensen la ubica a fines del siglo XIX. Nos inclinamos por esta segunda época que coincidiría con la temporalidad de la novela de Daudet en base algunos elementos del film, como la moda y los carruajes tirados a caballo, teniendo en cuenta que en la Buenos Aires del 1914 ya había tranvías, $13 \mathrm{~km}$ de subterráneo y automóviles.

3. Localidad de la zona norte del conurbano bonaerense en donde estaban emplazados los estudios Lumiton

4. De acuerdo con Karush (2013), los géneros musicales populares como el tango, el jazz, y el folklore forman parte del terreno de disputa en torno a "lo nuestro" y "lo extranjero". Están además asociados a la conformación de la tradición (lugar que ocupó el folklore) versus la modernidad encarnada en el jazz y a la que se pliega el tango mediante la transformación de su orgánico hacia la orquesta con la llamada Guardia Nueva y la modernización de los arreglos de la "escuela decareana". En este sentido, el folklore permanece como el género conservador de la tradición y la argentinidad rural.

5. Félix Pérez Cardozo fue un compositor e intérprete de arpa paraguayo, afincado en Buenos Aires desde 1931 en donde desarrolló una amplia carrera musical con la popularización de muchas de sus canciones. La coreografía fue realizada por Victoria Garabato y la idea de adaptación o estilización del baile folklórico aparece anunciado en los créditos iniciales como "coreografía estilizada" (00:01:33)

6. Para ampliar este tema sobre los imaginarios asociados a los territorios (el barrio, el centro, el arrabal) véase Del barrio al centro: imaginarios del habitar en las letras del tango rioplatense. (Sabugo, 2013) y La musicalización en el cine argentino en la década del '30: representaciones sonoras de la tensión entre lo nacional y lo extranjero. (Chalkho, 2015)

7. Con excepción del momento en que se cruzan cuando Irene va de visita a ver Raúl enfermo a la pensión y se da cuenta de su relación con Selva.

8. "No obstante, como he sostenido en este ensayo, la estructura del acto de mirar en el cine narrativo de ficción alberga una contradicción en sus propias premisas: la imagen femenina como amenaza de castración pone constantemente en peligro la unidad de la diégesis e irrumpe a través del mundo de la ficción como un fetiche intruso, estático, unidimensional. Así, las dos miradas presentes materialmente en el tiempo y en el espacio se subordinan de forma obsesiva a las necesidades neuróticas del ego masculino." (Mulvey, 2001, pag. 377)

9. En el personaje libertino del tío Silvino se cargan las frases más provocadoras, como por ejemplo cuando van a ir a la fiesta, le dice a Raúl: "y ahora vamos a festejarlo, a buscar dos menores para divertirnos" (00:07:45), o el diálogo en tono jocoso que mantiene con dos chicas jóvenes en la fiesta:

Joven 1: ¿canas? ¿Por lesiones o por robo?

Silvino: por robo, no puedo tener quietas las manos (mientras se le acerca y la toca)

Joven 2: y el señor tan calladito ¿estudia para orador?

Silvino: no, estudia para pianista, toca sin hablar... (risas) (00:09:00)

10. La cuestión del registro no es la única asociación que podemos establecer con la ópera, en donde se observan varios ejemplos de la heroína cortesana al modo de Safo, como 
la Violetta de La traviata (1853) de Giuseppe Verdi, basada a su vez en La dama de las Camelias de Alexandre Dumas, Manon Lescaut de Giacomo Puccini o Carmen de George Bizet. Para ampliar sobre la cuestión de la voz en el cine desde la perspectiva de género véase The acoustic mirror de Kaja Silverman (1988)

11. "Yo venía de hacer varios protagónicos cuando Lumiton me incluyó en Safo. Supongo que la empresa en forma inteligente -y esto que no parezca una cosa vanidosa- usó mi nombre y el éxito que ya había obtenido con mis anteriores filmes. Claro, era un personaje de "ingenua" y yo transitaba por esa línea en aquel momento, entonces convencieron a mi madre y a mi representante, don Ricardo Cerebello: "Es un buen papel, la vamos a cuidar, se va a destacar". Bueno, al fin "la nena" lo hizo, pero no, si volviera atrás no lo haría.

No fue un personaje que me gustara, aunque resultó una excelente película con una pareja magnífica como Mecha Ortiz y Roberto Escalada, pero no la recuerdo como una experiencia grata; no me sentí cómoda. Es más yo era sumamente joven y no sabía muy bien qué quería decir Safo, me sonaba a algo "non santo" en lo que no debería estar interviniendo: los amores de una mujer tempestuosa, su amante, en fin, piense que le estoy hablando de hace muchos años" (Gallina, 1997, pág. 85)

12. A partir de la década de 1990 cobra fuerza en el campo de la Musicología un conjunto de nuevas posiciones en torno al sentido musical que se enrolan abajo la denominación de Teoría tópica y que reconocen a Leonard Ratner como autor inaugural y a Raymond Monelle, Wye Allanbrook, Kofi Agawu y Robert Hatten como los autores de las principales ampliaciones. Esta teoría cobra especial relevancia al desplegar un corpus teórico y metodológico que intenta desentrañar un tema especialmente escurridizo para los estudios de la música: los sentidos que las músicas evocan y qué significados portan.

13. Señalamos al respecto, el trabajo de Janice Dickensheets, The Topical Vocabulary of the Nineteenth Century. (2012) sobre los tópicos del Romanticismo.

14. No existen muchos datos sobre la obra y vida de Joseph Kumok, (George Andreani) y gran parte de su magnífica obra se encuentra perdida. Destacamos al respecto la reciente publicación del artículo de Silvia Glocer George Andreani: Varsovia, Berlín, Praga, Buenos Aires que repone esta vacancia. (Glocer, 2018)

15. El inglés de los güesos (1940), Águila blanca (1941), La novia de primavera (1942), Locos de verano (1942), Noche de bodas (1942), Los chicos crecen (1942), Dieciséis años (1943), Safo, historia de una pasión (1943), La señora de Pérez se divorcia (1945), El canto del cisne (1945), Las seis suegras de Barba Azul (1945), La pequeña señora de Pérez (1944), La dama de la muerte (1946, Chile), Adán y la serpiente (1946), Con el diablo en el cuerpo (1947), Los verdes paraísos (1947), El ángel desnudo (1946), Adán y la serpiente (1946), Los pulpos (1948), Una atrevida aventurita (1948), La muerte camina en la lluvia (1948), ¿Por qué mintió la cigüeña? (1949), La trampa (1949), María Magdalena (1954),

16. Chsristensen explica su estrecho vínculo con Andreani de esta manera: "Una persona maravillosa (...) Un músico extraordinario y un amigo extraordinario (...) nos conocíamos tanto que él ya adivinaba lo que yo quería." (Russo \& Insaurralde, 2013, pág. 120)

17. Las transcripciones son nuestras

18. Mencionamos las revistas Radiolandia, Antena, Sintonía, entre las de mayor difusión. 


\section{Lista de Referencias Bibliográficas}

Allanbrook, W. (2014). The Secular Commedia: Comic Mimesis in Late Eighteenth-Century Music. Edited by Mary Ann Smart and. Berkeley: University of California Press.

Chalkho, R. (2015). La musicalización en el cine argentino en la década del '30: representaciones sonoras de la tensión entre lo nacional y lo extranjero. XXIX Jornadas de Investigación, XI Encuentro Regional SI+TER Investigaciones territoriales: experiencias $y$ miradas (pp. 241-250). Ciudad Autónoma de Buenos Aires: Universidad de Buenos Aires. Facultad de Arquitectura, Diseño y Urbanismo. Secretaría de Investigaciones.

Dickensheets, J. (2012). The Topical Vocabulary of the Nineteenth Century. Journal of Musicological Research, 31, 97-137.

España, C. (2000). Cine argentino. Industria y clasicismo. 1933-1956 Volumen I. Buenos Aires: Fondo Nacional de las Artes.

Fabbro, G. (2000). Lumiton. El berretín del cine. In C. España, Cine argentino. Industria y clasicismo. 1933/1956. Buenos Aires: Fondo Nacional de las Artes.

Gallina, M. (1997). Carlos Hugo Christensen. Historia de una pasión cinematográfica. Buenos Aires: Producciones Iturbe.

Glocer, S. (2016). Melodias del destierro: músicos judíos exiliados en la Argentina durante el nazismo (1933-1945). Buenos Aires: Gourmet Musical.

Glocer, S. (2018). George Andreani: Varsovia, Berlín, Praga, Buenos Aires. Cuadernos Judaicos, 35, 46-83.

Janin, A. (2015). Hombres de negro. Masculinidad y film noir en La trampa (de Carlos Hugo Christensen). Imagofagia, 11.

Karush, M. (2013). Cultura de clase. Radio y cine en la creación de una Argentina dividida (1920-1946). Buenos Aires: Ariel.

Kelly Hopfenblatt, A. (2014). Maduración, sexualidad y redefinición de reglas en el modelo de ingenuas del cine clásico argentino. El ojo que piensa. Revista de cine iberoamericano.

McClary, S. (2002). Feminine endings. Music, Gender \& Sexuality. Minneapolis: University of Minnesota Press.

McClelland, C. (2014). Ombra and Tempesta. In D. Mirka (Ed.), The Oxford Handbook of Topic Theory. Oxford: Oxford University Press.

McKee, E. (2012). Decorum of the Minuet, Delirium of the Waltz. A Study of Dance Music Relations in 3/4 Time. Bloomington \& Indianapolis: Indiana University Press.

Miller, N. (1999). In the Shadow of the State: Intellectuals and the Quest for National Identity in Twentieth-Cetury Spanish America . Londres: Verso.

Monelle, R. (2006). The musical topic: hunt, military, and pastoral. Indiana: Indiana University Press.

Mulvey, L. (1992). Visual Pleasure and Narrative Cinema. In M. Merck (Ed.), The Sexual Subject: Screen Reader in Sexuality (pp. 22-34). London \& New York: Routledge.

Mulvey, L. (2001). Placer visual y cine narrativo. In B. Wallis (Ed.), Arte después de la modernidad. Nuevos planteamientos en torno a la representación (pp. 365-377). Madrid: Akal.

Pardo, S., \& Croci, P. (2011). Safo, historia de una pasión: Tensión entre canon y ruptura en el primer melodrama erótico del cine argentino. Revista Imagofagia, 3. 
Radiolandia. (1945, enero 27). A los diecisiete años, dice Mirtha, he visto tornarse en realidad a casi todos mis sueños. (J. Korn, Ed.) Radiolandia, p. 31.

Radiolandia. (1945, mayo 12). Mecha Ortiz. (J. Korn, Ed.) Radiolandia.

Ramos López, P. (2003). Feminismo y música. Introducción crítica. Madrid: Narcea S.A. de Ediciones.

Ratner, L. (1980). Classic Music: Expression, Form, and Style. New York: Schirmer Books.

Regueira, F. (2012). Postulación de una pasión: la Argentina. Sobre Safo, historia de una pasión de Carlos H. Christensen . En Cinco films argentinos (págs. 69-168). Buenos Aires: Djaen.

Russo, G., \& Insaurralde, A. (2013). Más allá del olvido. Conversaciones inéditas con grandes del cine nacional. Ciudad Autónoma de Buenos Aires: Prosa Amerian Editores.

Sabugo, M. (2013). Del barrio al centro: imaginarios del habitar en las letras del tango rioplatense. Buenos Aires: Café de las Ciudades.

Sarlo, B. (1988). Una modernidad periférica. Buenos Aires 1920 y 1930. Buenos Aires: Nueva visión.

Silverman, K. (1988). The Acoustic Mirror. The Female Voice in Psychoanalysis and Cinema. Bloomington and Indianapolis: Indiana University Press.

Tagg, P. (1982). Analysing Popular Music: Theory, Method and Practice. Popular Music, 37-67.

Viñuela Suárez, L. (2003). La construcción de las identidades de género en la música popular. (U. J. Publicacions, Ed.) Dossiers feministes, 11-32.

Zbikowski, L. (2012). Music, Dance, and Meaning in the Early Nineteenth Century. Journal of Musicological Research, 31, 147-165.

\begin{abstract}
The article aims to study the relationship between music and the figures of women represented in the film Sapho, a passion story directed by Carlos Hugo Christensen. The director inaugurated a change in the cinematography of that time by introducing at the beginning of the $40 \mathrm{~s}$ audacious subjects such as eroticism, turbulent passions, suicide, betrayals or divorce.

The music was commanded to George Andreani, a composer born in Warsaw in 1901 who is formed musically in Berlin, Vienna, and Prague, and who before arriving in Argentina fleeing from Nazism, had already composed numerous soundtracks, and received awards in Czechoslovakia and France. From the film El inglés de los güesos (1940), Christensen and Andreani formed a close tandem between director and composer, as evidenced by the more than twenty titles in which they worked together.

The compositional cohesion of the music is based fundamentally on the use of the leitmotif of a Wagnerian imprint that is associated with the characters of Selva, the femme fatal, Irene the naive adolescent and Teresa, the puritanical aunt. Parallel to the musical construction of the characters, the musical soundtrack adheres to the dramatic arc underlining the moods and emotions. Andreani handles orchestration with expertise through a rich and contrasting use of the timbral palette, exploiting the resources of Romantic and Post-romantic languages.
\end{abstract}


The character of Selva (the femme fatal) played by Mecha Ortiz is leitmotivistically associated with a slow and pasty waltz, worked with dotted rhythms and with the tune played by the strings, with portamentos connoting the sensuality and density of this experienced woman. It is the most developed musical motif throughout the film and the one that suffers the greatest transformations. Its progressive rupture and fragmentation built by contrasts of register, orchestration, and rhythms generate the variety of moods as the plot is stressed. As a contrast, the musical motif of Irene (the naive) played by Mirtha Legrand is elegant and brilliant, associated with the musical topic of the minuet. The soundtrack presents a third motif, associated with Teresa (the protagonist's aunt) built on the topic of "the morning", a pastoral and bucolic style that not only represents the character but also the idyllic and Catholic rural space.

One of the findings of the work is the relationship between the stereotypes of women that appear in the films and their transcendence beyond the screen in the lives of the actresses. This issue is verified in the representation of movie stars in the magazines of the time analogously to the figures they represent in the films, both in the photographs as well as in the texts and interviews.

The article takes as a theoretical approach to gender theory, in particular, to the applications of this perspective to study film and music, such as the pioneering work of Laura Mulvey for classical cinema (Mulvey, 2001), the germinal book of Susan McClary, who approaches music from a feminist musicology (McClary, 2002) and the most recent approaches by Pilar Ramos López (Ramos López, 2003) and Laura Viñuela (Viñuela Suárez, 2003). For the approach of musical analysis, we consider the Topical Theory, (Ratner, 1980) that allows unraveling the construction of the musical sense through the topics as discursive units that make sense in a sociocultural context.

Methodologically, we made a cross between the tools of musical analysis with film analysis crossed with the proposed theoretical framework and supplemented with documentary sources such as interviews and press articles of the time.

Keywords: Film music - Argentine classic cinema - Female figures - Carlos Christensen George Andreani - Leitmotiv

Resumo: O artigo propõe-se estudar a relação entre a música e as figuras da mulher representadas no filme Safo, história de uma paixão dirigida por Carlos Hugo Christensen. O diretor inaugura uma mudança na cinematografía da época ao introduzir no início da década do '40 temáticas audaciosos como o erotismo, as paixões turbulentas, o suicídio, as traições ou o divórcio.

O encarregado da música é George Andreani, um compositor nascido em Varsovia em 1901 formado musicalmente em Berlim, Viena e Praga, e que dantes de chegar à Argentina fugindo do nazismo, já tinha composto numerosas bandas musicais e recebido prêmios em Checoslovaquia e França. A partir do filme O inglês dos güesos (1940), Christensen e Andreani formam um tándem estreito entre diretor e compositor, como fica evidenciado nos mais de vinte títulos nos que trabalham juntos. 
A coesão composicional da música está baseada fundamentalmente no uso do leitmotiv de impronta wagneriana que se apresenta associado às personagens de Selva, a femme fatal, Irene a adolescente ingénua e Teresa, a tia santa. Em forma paralela à construção musical das personagens, a banda musical adere-se ao arco dramático sublinhando os climas e emoções. Andreani maneja a orquestração com perícia através de um uso rico e contrastante da paleta tímbrica, explodindo os recursos das linguagens romântico e pós-romântico.

A personagem de Selva (a femme fatal) interpretado por Mecha Ortiz está sócio leitmotívicamente a um vals lento e pastoso, trabalhado com ritmos apuntillados e com a melodia a cargo das cordas, tocada com portamentos connotando a sensualidade e densidade desta mulher experimentada. É o motivo mais desenvolvido ao longo do filme e o que sofre as maiores transformações. Sua progressiva ruptura e fragmentação construída mediante contrastes de registro, orquestração e ritmos, gera a variedade de climas conforme a trama se tensiona.

Em contraste, o motivo musical de Irene (a ingênua) interpretado por Mirtha Legrand é elegante e brilhante, sócio ao tópico musical do minuet. A trilha corrente apresenta um terceiro motivo, associado a Teresa (a tia do protagonista) construído em base ao tópico da "manhã", de carácter pastoral e bucólico não só representa à personagem senão também ao espaço rural idílico e católico.

Uma das descobertas do trabalho é a relação entre os estereótipos de mulher que aparecem nos filmes e seu trascendencia para além da tela na vida das actrizes, questão que se verifica na representação das estrelas do cinema nas revistas da época de maneira análoga às figuras que representam nos filmes, tanto nas fotografias como os textos e entrevistas. O artigo leva a abordagem no enfoque teórico à teoria de gênero, em particular, aos aplicativos desta perspectiva para estudar o cinema e a música, como o trabalho pioneiro de Laura Mulvey para o cinema clássico (Mulvey, 2001), o livro germinal de Susan McClary que aborda a música desde uma musicología feminista (McClary, 2002) e os enfoques mais recentes de Pilar Ramos López (Ramos López, 2003) e Laura Viñuela (Viñuela Suárez, 2003). Para a abordagem da análise musical consideramos à Teoria Tópica, (Ratner, 1980) que permite desvendar a construção do sentido musical através dos tópicos como unidades discursivas que cobram sentido num contexto sociocultural.

Metodologicamente, fizemos um cruzamento entre as ferramentas da análise musical com a análise de filmes cruzados com o marco teórico proposto e complementado com fontes documentais como entrevistas e artigos de imprensa da época.

Palavras chave: Música cinematográfica - Cinema clássico argentino - Figuras femininas - Carlos Christensen - George Andreani - Leitmotiv

[Las traducciones de los abstracts fueron supervisadas por el autor de cada artículo] 